\title{
Protons Selectively Induce Lasting Excitation and Sensitization to Mechanical Stimulation of Nociceptors in Rat Skin, in vitro
}

\author{
Kay H. Steen, Peter W. Reeh, Fernand Anton, and Hermann O. Handwerker \\ Institut für Physiologie und Biokybernetik, Universität Erlangen-Nürnberg, D-8520 Erlangen, Germany
}

In ischemic and in inflamed tissues, $\mathrm{pH}$ levels down to $\mathbf{5 . 4}$ have been measured, and this local acidosis may contribute to pain and hyperalgesia in disease states. To evaluate the role of acid pH in nociception, we have studied identified primary afferents in a rat skin-saphenous nerve preparation in vitro where the receptive fields can be superfused at the highly permeable corium side with controlled solutions. The nerve endings were exposed to $\mathrm{CO}_{2}$-saturated synthetic interstitial fluid (SIF; pH 6.1) and to carbogen-gassed SIF phosphate buffered to different acid $\mathrm{pH}$ levels $(5 \mathrm{~min}$ duration, 10 min intervals). Mechanical thresholds were repeatedly tested in a "blind" fashion by von Frey hair stimulation.

Low-threshold mechanosensitive $A \beta-(n=12)$ and $A \delta$ fibers ( $n=11$ ) were not excited or sensitized by acid $\mathrm{pH}$ levels. In 24 of 96 nociceptor type C- and A $\delta$-fibers, irregular low-frequency discharge with poor response characteristics was induced. However, a distinct subpopulation of mechanoheat sensitive, "polymodal" C-units $(n=25 ; 38 \%)$ showed stimulus-related responses increasing with proton concentration and encoding the time course of the $\mathrm{pH}$ change. Threshold levels were found to range from $\mathrm{pH} 6.9$ to 6.1; mean maximum discharge was at pH 5.2. All such fibers responded to $\mathrm{CO}_{2}$ as well as to phosphate-buffered solution at the same $\mathrm{pH}$ 6.1. The $\mathrm{CO}_{2}$ responses, however, displayed significantly shorter latencies and more pronounced dynamic phases. The carboanhydrase blocker acetazolamide markedly delayed and reduced the $\mathrm{CO}_{2}$ responses. Prolonged application of acid pH (30 min) evoked nonadapting activity irrespective of oxygen supply. Many, but certainly not all, fibers sensitive to protons were also driven by capsaicin $\left(10^{-6} \mathrm{M}, 10^{-5} \mathrm{M}\right)$ and vice versa. Repeated or prolonged treatment with low $\mathrm{pH}$ induced a significant and lasting decrease of the mechanical (von Frey) thresholds in almost all C-fibers tested (from 35 to $16 \mathrm{mN}$, on average), and this occurred whether or not a fiber was excited by protons. The sensitizing effect was more pronounced the higher the initial von Frey thresholds ( 0.75 rank correlation). This sensitization to mechanical stimulation was in contrast to the combined action of other inflammatory mediators, bradykinin,

Received Apr. 1, 1991; revised July 30, 1991; accepted Aug. 5, 1991.

This work was supported by a DFG grant to P.W.R. We appreciate the advice of Prof. S. Kallert. Thanks are due to K. Burian and R. Albrecht for their excellent technical assistance.

Correspondence should be addressed to Prof. Dr. P. W. Reeh, Institut für Physiologie und Biokybernetik, Universität Erlangen-Nürnberg, Universitätsstraße 17, D-8520 Erlangen, Germany.

Copyright (C) 1992 Society for Neuroscience $0270-6474 / 92 / 120086-10 \$ 05.00 / 0$
5-HT, histamine and prostaglandin $\mathrm{E}_{2}$. In conclusion, we suggest that pH sensitivity of nociceptors may be an important source of pain and hyperalgesia.

Before the discovery of specific tissue hormones mediating symptoms of inflammation, the medical community was in agreement that abnormal physicochemical properties of the inflammatory exudate produce the pain and the hyperalgesia in injured or inflamed tissue. Indeed, high osmolarities, high potassium levels, and in particular, high hydrogen ion concentrations were found in inflammation (down to $\mathrm{pH} 5.4$ ), in fracture-

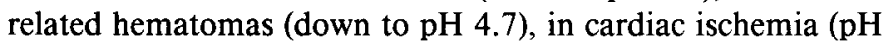
5.7), and even in and around malignant tumors (Häbler, 1929; Revici et al., 1949; Peer, 1955; Jacobus et al., 1977). A positive correlation between pain and local acidity in arthritis was established, and painful abscesses were even treated for relief with bicarbonate injections (von Gaza and Brandi, 1927; Häbler, 1930). Human psychophysiologists evaluated the role of $\mathrm{pH}$ in experimental pain, but results remained somehow inconclusive (von Gaza and Brandi, 1926; Lindahl, 1961; Keele and Armstrong, 1964). The investigators met with the problem of maintaining a constant, low $\mathrm{pH}$ (in the skin) against the buffering capacity and counterregulation of the intact organism. In consequence, they only found transient algesic effects of acid $\mathrm{pH}$, which could seemingly not explain ongoing pain from inflammation.

On the other hand, the hormonal mediators of inflammation were not completely satisfactory in explaining pain of peripheral origin. Two of them, bradykinin and 5-HT, did excite a proportion of nociceptors, but they rapidly lost action due to tachyphylaxis (Kanaka et al., 1985; Kumazawa et al., 1987; Handwerker et al., 1990a; Lang et al., 1990). Only an ample combination of mediators, bradykinin, 5-HT, histamine, and prostaglandin, in high, perhaps unphysiological concentration $\left(10^{-5} \mathrm{M}\right)$ was able to drive cutaneous nociceptors continuously in vitro (H. Reischl, K. H. Steen, and P. W. Reeh, unpublished observations; see Handwerker and Reeh, 1991, for discussion). This "inflammatory soup" was expected to induce nociceptor sensitization to mechanical (von Frey) stimulation, since mechanical hyperalgesia is a regular symptom accompanying inflammatory diseases. However, it failed (Kessler et al., 1989; see also Fig. $8 B$ ). Thus, no chemical condition increasing nociceptor sensitivity to mechanical stimuli could yet be established for the skin, in contrast to the joint model where nociceptor sensitization to passive movement could readily be demonstrated to result from application of bradykinin and of prostaglandin (Neugebauer et al., 1989). The only explanation for cutaneous hyperalgesia appeared to be a segmental sensiti- 
7ation of spinothalamic, second-order neurons in the spinal dorsal horn (Woolf, 1983; Willis, 1990; Woolf and King, 1990).

To elucidate a possible role of acid $\mathrm{pH}$ in nociception, we addressed a number of open questions. Which type of nerve endings would be excited, how selectively, and to what extent? Can primary afferents encode the degree and the temporal profile of acidification in a pathophysiologically relevant range? Is there adaptation during long-standing acid $\mathrm{pH}$ and tachyphylaxis upon repeated application? Does the sensitivity to mechanical and/ or thermal stimulation change following low $\mathrm{pH}$ treatment?

Preliminary accounts of the present work have previously been communicated in abstract form (Handwerker et al., 1990b; Steen et al., 1990).

\section{Materials and Methods}

For the purpose of this study, obviously a rigid control over the chemical environment of cutaneous nerve endings was needed. Therefore, we employed a rat skin-nerve preparation in vitro that has previously been described in detail (Reeh, 1986, 1988).

Preparation. The preparations were taken from 63 male Wistar rats (350-450 gm body weight) anesthetized with thiopental sodium (120 $\mathrm{mg} / \mathrm{kg}$, i.p.). The complete skin of the dorsal hind paw and of the lower third of the leg was subcutaneously dissected in continuity with the saphenous nerve and excised. The preparations were made from both legs of the animal; the second one was stored at $4^{\circ} \mathrm{C}$ in oxygenated electrolyte solution and sometimes used later the same day. After skin excision, the rats were killed with an intracardial injection of Xylocain. The skin was pinned, hairy side down, in one chamber of an organ bath. The saphenous nerve was threaded through a hole into a second chamber, where small filaments were teased and further subdivided until single-unit activity could be recorded via gold wire electrodes in a layer of paraffin oil.

The preparation was superfused $(16 \mathrm{ml} / \mathrm{min})$ with synthetic interstitial fluid (SIF; Bretag, 1969), continuously bubbled with carbogen $\left(95 \% \mathrm{O}_{2}\right.$, $5 \% \mathrm{CO}_{2}$ ). The temperature was thermostatically controlled to $32^{\circ} \mathrm{C}$ $\left( \pm 0.5^{\circ} \mathrm{C}\right)$.

Determination of sensory properties. Receptive fields of single units were searched for by probing the corium side of the skin with a blunt glass rod. The nerve endings were electrically stimulated in their receptive fields via Teflon-insulated steel microelectrodes (1-10 M $\Omega$ ) to measure conduction velocity and to establish the identity of mechanically and electrically evoked impulses with the "collision technique." The thresholds to mechanical stimulation were tested (at the corium side) with a set of polyamide von Frey hairs calibrated in millinewtons in the form of a geometric series $\left(x_{i}=x_{i-1} \sqrt{2}\right.$; see ordinates in Figs. 7,8$)$ and equipped with uniform flat tips of $0.9 \mathrm{~mm}$ diameter. First, the range in which the threshold was to be expected from the glass rod probing was roughly determined with ascending or descending forces of the von Frey hairs. Then followed a fine determination of the von Frey threshold at the most sensitive spot of the receptive field using three to four probes of adjacent force values that were applied in an up-and-down variation of 7-11 probings. The number of probes was then reduced to the two critical ones, and the variation continued (four more probings). Each probing consisted of four to six single trials of 1-2 sec duration, and that von Frey hair strength was taken as threshold that evoked a discharge in about half of the trials. When a changing von Frey threshold was followed up in closely spaced intervals (see Fig. 7), the procedure was reduced to using two, eventually changing probes of adjacent force values. The critical measurements, before and after experimental treatments, were always double-checked by other experimenters who did not know about the "history" of the unit under investigation. Almost no discrepancies between the determinations of the different experienced persons occurred.

The heat responsiveness was examined by focusing a halogen bulb through the translucent bottom of the skin chamber onto the epidermal side of the receptive field. At the opposite corium side, the temperature was feedback controlled with a thermocouple, and for stimulation, it was raised from $32^{\circ} \mathrm{C}$ to $46^{\circ} \mathrm{C}$ over $20 \mathrm{sec}$, which corresponds to a rise from $32^{\circ} \mathrm{C}$ to $52^{\circ} \mathrm{C}$ at the epidermal surface (Reeh, 1986). To prevent measuring errors due to thermal convection, a metal ring (see below) was placed over the respective corium area and its fluid content was evacuated. For cold stimulation, the ring was filled with cold SIF $\left(4^{\circ} \mathrm{C}\right)$ and the time course of the temperature was monitored.

Chemical stimulation. The metal rings to isolate receptive fields were also used for chemical stimulation. They had inner diameters of 6.6$9.6 \mathrm{~mm}$ (height, $8 \mathrm{~mm}$ ) and comprised volumes of $0.3-0.6 \mathrm{ml}$, which were perfused at $38.5^{\circ} \mathrm{C}$ with $2.25 \mathrm{ml} / \mathrm{min}$. The perfusion rate was chosen to produce a turbulent flow. When the perfusion was switched from normal SIF to stimulating solutions or vice versa, the ring chamber was emptied just prior to the arrival of the new solution in order to provide an instantaneous change of the fluid. The chemical stimulations followed different experimental protocols that are displayed along the abscissas of the figures (see Results). Most frequently, stimuli were applied for $5 \mathrm{~min}$ followed by $10 \mathrm{~min}$ washout.

The different $\mathrm{pH}$ solutions were made up in two ways on the basis of SIF. This bicarbonate-containing solution of salts and sugars was continuously gassed with pure $\mathrm{CO}_{2}\left(\mathrm{CO}_{2}-\mathrm{SIF}\right)$, which leads to $\mathrm{pH} 6.1$. Alternatively, the sodium bicarbonate $(26.2 \mathrm{~mm})$ normally contained in SIF was replaced by various proportions of $\mathrm{NaH}_{2} \mathrm{PO}_{4}$ and $\mathrm{Na}_{2} \mathrm{HPO}_{4}$ (PB-SIF) to produce different buffered $\mathrm{pH}$ levels. The $\mathrm{pH}$ was measured and adjusted with a few drops of either $\mathrm{HCl}$ or $\mathrm{NaOH}$ before each application, and the phosphate-buffered solutions were continuously bubbled with carbogen.

Data processing. The single nerve fiber activity was passed through a window discriminator and then continuously recorded on an AT 386 computer using the CED 1401 interface and software (MRATE). The magnitude of the responses to $\mathrm{pH}$ stimulation was assessed as the total number of spikes counted during $15 \mathrm{~min}$ after stimulus onset, irrespective of the actual duration of the response, which usually was much shorter. Nonparametric statistical comparisons were made using the Wilcoxon matched pairs test.

\section{Results}

Altogether, 114 primary afferents out of 10 different categories from the hairy skin of the rat's hind paw were examined in this study (Table 1). The units were categorized using established criteria of sensory properties and of conduction velocities (Lynn and Carpenter, 1982; Fleischer et al., 1983). Although these criteria have previously been determined using in vivo preparations of the rat saphenous nerve, they were readily applicable to the in vitro conditions reported here. Some minor quantitative differences in receptive properties, such as lower von Frey thresholds, lower conduction velocities, and apparently lower heat thresholds were to be traced back to methodical differences (Reeh, 1986, 1988) and did not create conflicts in fiber categorization.

\section{Selectivity of $p H$ effect}

The relative proportions of fiber types in Table 1 are not representative, since there was a deliberate search bias in favor of small-caliber, nociceptive units. However, 17 low-threshold mechanosensitive $\mathrm{A} \beta$ - and $\mathrm{A} \delta$-fibers with rapidly (including "down hair") and slowly adapting receptors were tested with different acid $\mathrm{pH}$ solutions and neither excited nor sensitized. With $\mathrm{CO}_{2}$-saturated superfusion, they quickly and completely lost their mechanosensitivity but rapidly recovered during washout with oxygenated SIF; electrical excitability was unchanged throughout this process (in the three cases tested).

A large number of the C- and A $\delta$-fibers were of nociceptor type: mechano-heat sensitive ("polymodal"; $\mathrm{MH}$ ), mechanocold sensitive (MC), and high-threshold mechanosensitive (HTM). About a quarter of these slowly conducting units in each category developed very low frequency irregular discharge ( $<12 / \mathrm{min}$ ) during acid $\mathrm{pH}$ superfusion for $5 \mathrm{~min}$, which could only slowly be "washed out" (20-30 min) and was poorly related to steps in the actual pH. This pattern was called "activated" in Table 1. Those fibers were not further investigated. In contrast, a distinct subpopulation (38\%) mainly of the C-MH no- 
Figure 1. Specimen from a C-MH nociceptor responding to different $\mathrm{pH}$ stimuli and to capsaicin (Caps.; $10 \mathrm{~min}$ interval, 5 min duration). The upper trace displays the delayed changes of the von Frey threshold induced by chemical treatments. mech., mechanical stimulation.

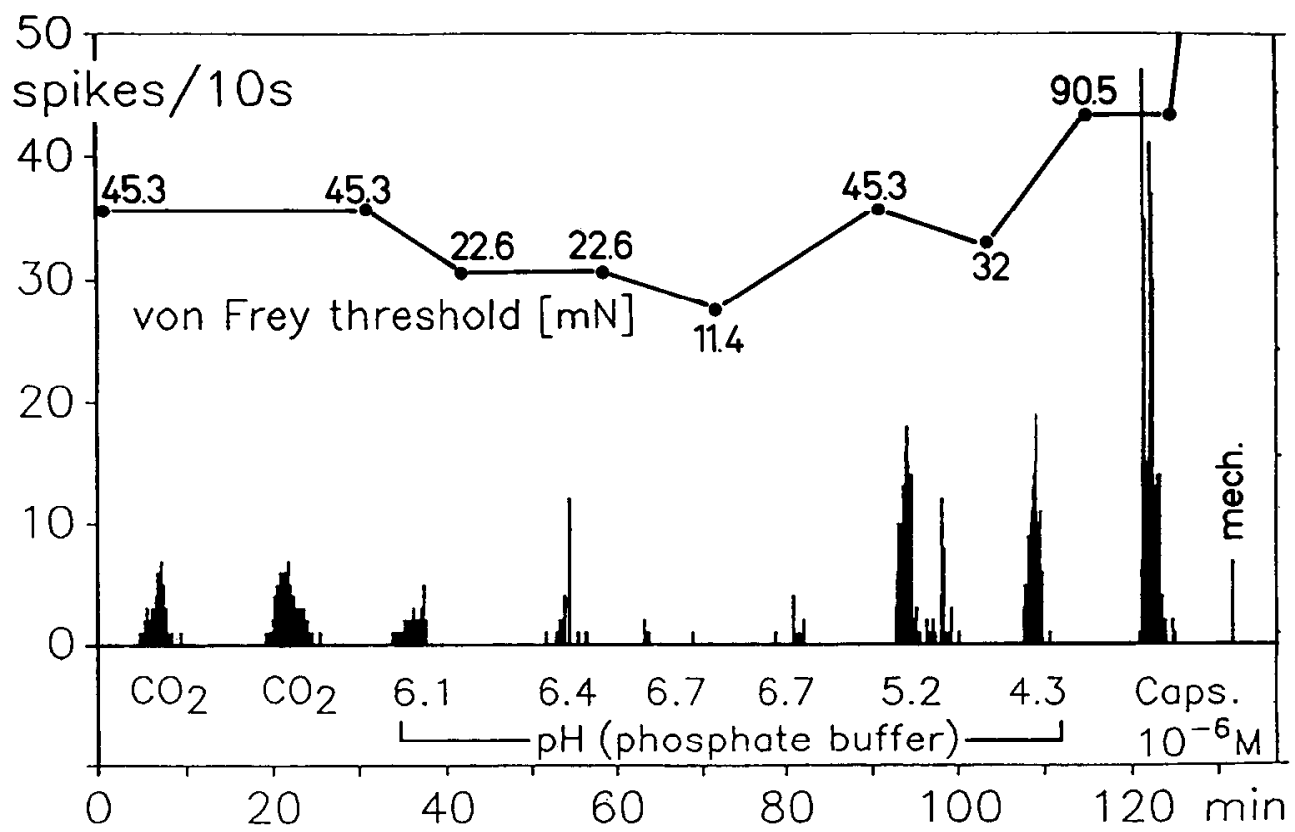

ciceptors showed dose- and duration-dependent vivid responses to acid pH superfusion (Figs. 1, 2). This group was not to be distinguished from other C-MH units in terms of conduction velocity or thermal or mechanical sensitivity. All such $\mathrm{pH}$-sensitive fibers responded to $\mathrm{CO}_{2}$-SIF as well as to the PB-SIF solution of the same $\mathrm{pH} 6.1$. The $\mathrm{CO}_{2}$ responses, however, displayed more pronounced dynamic discharge phases and significantly shorter latencies (44 vs. $91 \mathrm{sec}$ on average; Fig. 3). Consequently, the mean responses were somewhat larger than with PB-SIF at pH 6.1 (Fig. 4).

\section{Dose-response relation}

All units unresponsive to $\mathrm{CO}_{2}$-SIF were further treated with PB-

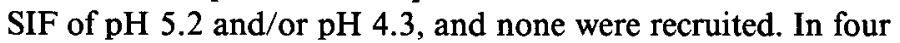
$\mathrm{C}-\mathrm{MH}$ fibers sensitive to $\mathrm{CO}_{2}$-SIF, the $\mathrm{pH}$ range $7.0-6.1$ was investigated using PB-SIF set to closely graduated $\mathrm{pH}$ values, and rather distinct threshold levels between $\mathrm{pH} 6.95$ and 6.1 were found, "threshold" being defined as the $\mathrm{pH}$ producing the smallest, reproducible response (see Figs. 1, 2). This range of $\mathrm{pH}$ thresholds seems to be well established, since in a recent study on inflammatory mediators SIF at $\mathrm{pH} 7.0$ was used as a control superfusion in nine C-MH fibers and none were excited (Kessler et al., 1989).
On average, the magnitude of the nociceptor responses to repeated $\mathrm{CO}_{2}$-SIF stimulation was very well reproducible, even after long series of pH stinuli (Fig. 4). Thus, apart from the individual response variability, no systematical tachyphylaxis occurred with repeated pH stimulation. From $\mathrm{pH} 6.1$ to $\mathrm{pH} 5.2$ PB-SIF, all units tested increased their response, by about two times on average, while only two units further increased it to pH 4.3 (Fig. 4). The discharge of most units and the mean response magnitude showed a decline from $\mathrm{pH} 5.2$ down to $\mathrm{pH}$ 4.3 , indicating an inversely U-shaped dose-response relationship. From the more closely graduated, individual dose-response curves (Fig. $2 B$ ), a steeper slope (in log-log coordinates) seemed to prevail in a range of smaller proton concentrations while the curves tended to flatten with higher levels of acidity.

\section{Nonadapting excitation}

Since no tachyphylaxis had occurred with the sequence of $\mathrm{pH}$ stimuli chosen, we tried prolonged application of $\mathrm{CO}_{2}-\mathrm{SIF}(n=$ 4) and PB-SIF at pH $6.1(n=2)$ for $30 \mathrm{~min}$ and longer on receptive fields of $\mathrm{pH}$-sensitive $\mathrm{C}-\mathrm{MH}$ fibers. In all cases, we recorded a continuous nonadapting activity with variable duration of afterdischarge as response (Figs. 5, 6). There was no obvious difference in effect between the deoxygenated and the

Table 1. Primary afferents out of $\mathbf{1 0}$ sensory categories from rat hairy skin recorded in saphenous nerve

\begin{tabular}{|c|c|c|c|c|c|c|c|c|c|c|c|}
\hline & \multicolumn{4}{|c|}{ C-fibers $(n=91)$} & \multicolumn{5}{|c|}{ A $\sigma$-fibers $(n=11)$} & \multicolumn{2}{|c|}{$\begin{array}{l}\text { A } \beta \text {-fibers } \\
(n=12)\end{array}$} \\
\hline & $\overline{\mathrm{MH}}$ & MC & HTM & LTM & $\overline{\mathrm{MH}}$ & $\mathrm{MC}$ & HTM & LTM & RA-LTM & RA & SAI \\
\hline Fibers tested & 65 & 15 & 10 & 1 & - & 1 & 5 & 1 & 4 & 9 & 3 \\
\hline Responded & $25(=38 \%)$ & 0 & 1 & 0 & - & 0 & 0 & 0 & 0 & 0 & 0 \\
\hline Activated & 16 & 5 & 3 & 0 & - & 0 & 0 & 0 & 0 & 0 & 0 \\
\hline
\end{tabular}

A total of 114 primary afferents was examined. There was a deliberate search bias in favor of small-caliber nociceptive units "Tested" means repeated superfusion of receptive field for 5 min at 10 min intervals with $\mathrm{CO}_{2}$-SIF (pH 6.1) and, in case of unresponsiveness, with PB-SIF (pH 5.2 and/or 4.3). "Responded" means a coherent discharge of at least 20 spikes that started during superfusion with $\mathrm{CO}_{2}$-SIF and was reproduced in a second trial. "Activated" means induction of low-frequency irregular discharge during acid $\mathrm{pH}$ superfusion that could only slowly be "washed out" and was poorly related to the actual pH (see text). MH, mechano-heat sensitive ("polymodal"); MC, mechano-cold sensitive; HTM, high-threshold mechanosensitive; LTM, low-threshold mechanosensitive; RA, rapidly adapting; SAI, slowly adapting type I (Merkel cell complex). Note: RA-LTM A $\delta$-fibers likely represent "downhair" receptors. 



Figure 2. A, Spike density histograms from a C-MH fiber. Arrows point to consecutive record to indicate order of trials. $B$, Dose-response curves ( $\log -\log$ ) of four C-MH fibers normalized to the individual response to $\mathrm{CO}_{2}$-SIF. The solid circles represent data from fiber in $A$; the triangles relate to the fiber in Figure 1. Arrows point to subthreshold $\mathrm{pH}$ values tested. $C$, Data from $B$ in $\log$-linear coordinates.

oxygenated stimulus solution except for the previously noted initial dynamic discharge often seen with $\mathrm{CO}_{2}$-SIF and a somewhat delayed washout of the PB-SIF effect (Fig. 5). During two of the sustained $\mathrm{CO}_{2}$-SIF treatments, the carboanhydrase inhibitor acetazolamide $\left(10^{-5} \mathrm{M}\right)$ was added for $10 \mathrm{~min}$ (Fig. $6 \mathrm{~B}$ ). This resulted in a marked suppression of the responses, as could be expected from a decrease of the intracellular (or intramembraneous) transformation from $\mathrm{CO}_{2}$ to protons (Thomas, 1976). When acetazolamide was used $(n=2)$ to pretreat receptive fields for $5 \mathrm{~min}$ prior to $\mathrm{CO}_{2}$-SIF stimulation, the effect was to delay and reduce the responses in a way that they became very similar to the PB-SIF responses of the respective units.

\section{Sensitization to mechanical stimuli}

A major finding of the present study was that prolonged or repeated treatment of receptive fields with acid $\mathrm{pH}$ could sensitize C-MH nociceptors to punctate mechanical (von Frey) stimulation. This sensitization obviously resulted from a cumulative effect; it took at least two successive applications of either $\mathrm{CO}_{2}$ - or PB-SIF at pH 6.1 to occur and three or four to be completed (Fig. 7). Of course, the von Frey thresholds could only be tested when the pH-induced discharge had ceased; "activated" units were therefore not investigated. Fortunately, however, the effect persisted during the washout period for about $15 \mathrm{~min}$. Furthermore, the sensitizing effect was present in C-MH nociceptors that did not respond with any discharge to the repeated pH treatments (e.g., unit shown in Fig. 7). In three experiments, the altered von Frey thresholds were followed up for longer periods, and a rebound desensitization was found in two cases that could be reversed with resumed $\mathrm{CO}_{2}$-SIF superfusion.

No evidence for a similar sensitization of C-MH units to heat stimulation could be found in the period after the $\mathrm{pH}$-induced discharge had ceased. The average heat threshold (temperature at first spike) of $17 \mathrm{pH}$-responsive $\mathrm{C}-\mathrm{MH}$ fibers was $39.7^{\circ} \mathrm{C}$ $( \pm 3.5 \mathrm{SD})$ before standard $\mathrm{pH}$ treatments and $38.0^{\circ} \mathrm{C}( \pm 4.2 \mathrm{SD})$ after the following washout $(10 \mathrm{~min})$; the small difference was not significant (Wilcoxon test). The same was true for seven $\mathrm{pH}$ insensitive $\mathrm{C}-\mathrm{MH}$ units $\left(40.8^{\circ} \mathrm{C}\right.$ vs. $\left.38.7^{\circ} \mathrm{C}\right)$. This does not, however, exclude the possibility of a short, transient sensitization to heat, since heat stimuli were not applied during acid $\mathrm{pH}$ superfusion.

The quantitative aspects of $\mathrm{pH}$-induced sensitization to mechanical stimulation were analyzed in a mixed, representative population of pH-excitable and -unexcitable polymodal C-nociceptors that had all received an initial standard treatment with three successive applications of $\mathrm{pH} 6.1$ (5 min, either $\mathrm{CO}_{2}$ - or PB-SIF) at 10 min intervals. The von Frey threshold during the third washout interval was measured ("blind" testing; see Materials and Methods) and compared to the initial value. The effect was highly significant and of considerable magnitude, de- 




Figure 3. Latencies of individual C-MH fiber responses to different solutions of $\mathrm{pH} 6.1, \mathrm{CO}_{2}$-SIF versus PB-SIF; significantly delayed responses to phosphate buffer, $44 \mathrm{sec}$ with $\mathrm{CO}_{2}$-SIF versus $91 \mathrm{sec}$ with PB-SIF on average (Wilcoxon test; $p=0.018 ; n=8$ ). $\mathrm{CO}_{2}$-SIF latencies were not significantly different $(n=7)$.

creasing the average von Frey threshold from 35 to $16 \mathrm{mN}$ (Fig. $8 A$ ). More than half of the fibers lowered their thresholds to one-half or one-quarter of their initial values. Every one of the $\mathrm{pH}$-sensitive C-MH units increased its von Frey sensitivity, as did six of nine $\mathrm{pH}$-unresponsive fibers, while three remained unchanged. In Figure $8 B$, data of another study of the same

\begin{tabular}{lll}
\hline Table 2. Partial lack of cross-sensitivity of C-MH fibers to capsaicin \\
and $\mathrm{CO}_{2}$-SIF
\end{tabular}

laboratory are displayed as a control for the relative stability of von Frey thresholds (Kessler et al., 1989). In this work, identical methods and the same time protocol as here were used, but the receptive fields of polymodal C-nociceptors were treated with "inflammatory soup," a mixture of bradykinin, histamin, 5-HT, and prostaglandin $E_{2}$ (all at $10^{-5} \mathrm{M}$ ) in SIF with elevated potassium (7 mM), proton concentration ( $\mathrm{pH} 7.0$ ), and temperature $\left(38.5^{\circ} \mathrm{C}\right)$. Though this algogenic solution excited all of the displayed units, it did not significantly alter the von Frey thresholds.

Other nociceptive types of nerve endings-A $\delta$-HTM $(n=5)$, C-HTM $(n=5)$, and C-MC $(n=7)$-were also subject to the standard pH 6.1 treatment and von Frey threshold recording. No changes of mechanical sensitivity were observed even though one of the units was $\mathrm{pH}$ responsive. Additional exposure to $\mathrm{pH}$ 4.3 induced a desensitization in seven of those fibers. Also, eight $\mathrm{C}$-MH fibers were further treated with PB-SIF of $\mathrm{pH}$ lower than 6.1, and all maintained their von Frey thresholds after $\mathrm{pH} 5.2$, but six of the fibers were markedly desensitized after $\mathrm{pH} 4.3$ (see Fig. 1 for specimen). Again, this included fibers unexcited by low $\mathrm{pH}$. Thus, the inversely U-shaped dose-response curve of the $\mathrm{pH}$ excitability (Fig. 4) seems also to apply to the $\mathrm{pH}$ induced changes in mechanical sensitivity.

\section{Cross-sensitivity to capsaicin}

Some recent evidence from different indirect models of nociception suggests a close similarity between the action of low $\mathrm{pH}$ and that of capsaicin (Bevan and Yeats, 1991). In the present study, we therefore tested receptive fields of $15 \mathrm{C}-\mathrm{MH}$ fibers with both $\mathrm{CO}_{2}$-SIF and capsaicin, the latter first at $10^{-6} \mathrm{M}$ and then, if ineffective, at $10^{-5} \mathrm{M}$ concentration. Capsaicin was always given as a final application, since the concentrations used may induce lasting desensitization to chemical stimuli (Lang et al., 1990). Table 2 shows that a similar proportion of the units were driven by either of the substances but that a complete cross-sensitivity was clearly lacking. Capsaicin mostly caused a profound desensitization to von Frey stimulation (see Fig. 1 for specimen). As in a previous study, a sensitization to mechanical stimuli was never seen (Lang et al., 1990).

\section{Discussion}

The cause of clinical pain is still not completely understood. It is not clear by which mechanisms such different diseases as arterial occlusion in working heart or leg, hematoma, inflammation, and malignant tumor can constantly excite nociceptors and enhance their sensitivity to harmless mechanical forces. Local acidosis has repeatedly been suggested as the "missing link" between disease and pain (von Gaza and Brandi, 1926; Keele and Armstrong, 1964; Lindahl, 1974). Indeed, a number of painful diseases have high extracellular proton concentrations in common (see introductory remarks), whereas a painless though destructive inflammation, the tuberculous abscess, produces an inflammatory exudate of normal pH (von Gaza and Brandi, 1926). The present study has now described a large subpopulation of the "polymodal" C-MH fibers, the most frequent and widespread type of nociceptor, that was exquisitely sensitive to shifts of the local pH into or in a range relevant to disease states. This group of primary afferents is not much smaller than the one sensitive to bradykinin ( $56 \%$ of the polymodals), thus far the most potent endogenous algogenic (Lang et al., 1990). The unique properties of $\mathrm{pH}$ sensitivity, showing up mainly during sustained acidosis, could only be discovered under in vitro con- 




ditions because of the buffering capacities in vivo of intact blood supply (see below). Thus, the role of protons as an algogenic principle was late to be recognized. Indirectly, the $\mathrm{pH}$ sensitivity has probably been encountered before when muscle nociceptors were observed to be strongly excited by contraction during arterial occlusion (Mense and Stahnke, 1983). In the beating heart, this condition leads to intracellular $\mathrm{pH}$ levels down to 5.7 (PooleWilson, 1978).

\section{Characteristics of $\mathrm{pH}$ sensitivity}

In a cutaneous in vitro preparation, the isolated perfused rabbit ear, excitation of primary afferents with acid $\mathrm{pH}$ has previously been tried, unsuccessfully since the periods of exposure were probably too short (Perl, 1976). In our preparation, it took about $1.5 \mathrm{~min}$, on average, of continuous phosphate buffer superfusion to induce nociceptor discharge, and this was certainly not due

Figure 4. Individual magnitudes of C-MH unit responses to different pH stimuli: significant increase from $\mathrm{pH} 6.1$ to 5.2 (Wilcoxon test; $n=$ 6); no significant differences between all mean $\mathrm{CO}_{2}-\mathrm{SIF}$ responses and between $\mathrm{PB}-\mathrm{SIF}$ at $\mathrm{pH}$ 6.1 versus previous $\mathrm{CO}_{2}$-SIF response. The heavy line connects the means of the data columns. Note absence of tachyphylaxis in population response. Note here that $15 \mathrm{~min}$ was an operationally defined sampling period unrelated to the actually shorter response duration. Thus, spikes $/ 15 \mathrm{~min}$ does not represent an average discharge rate but rather the total number of spikes per response.

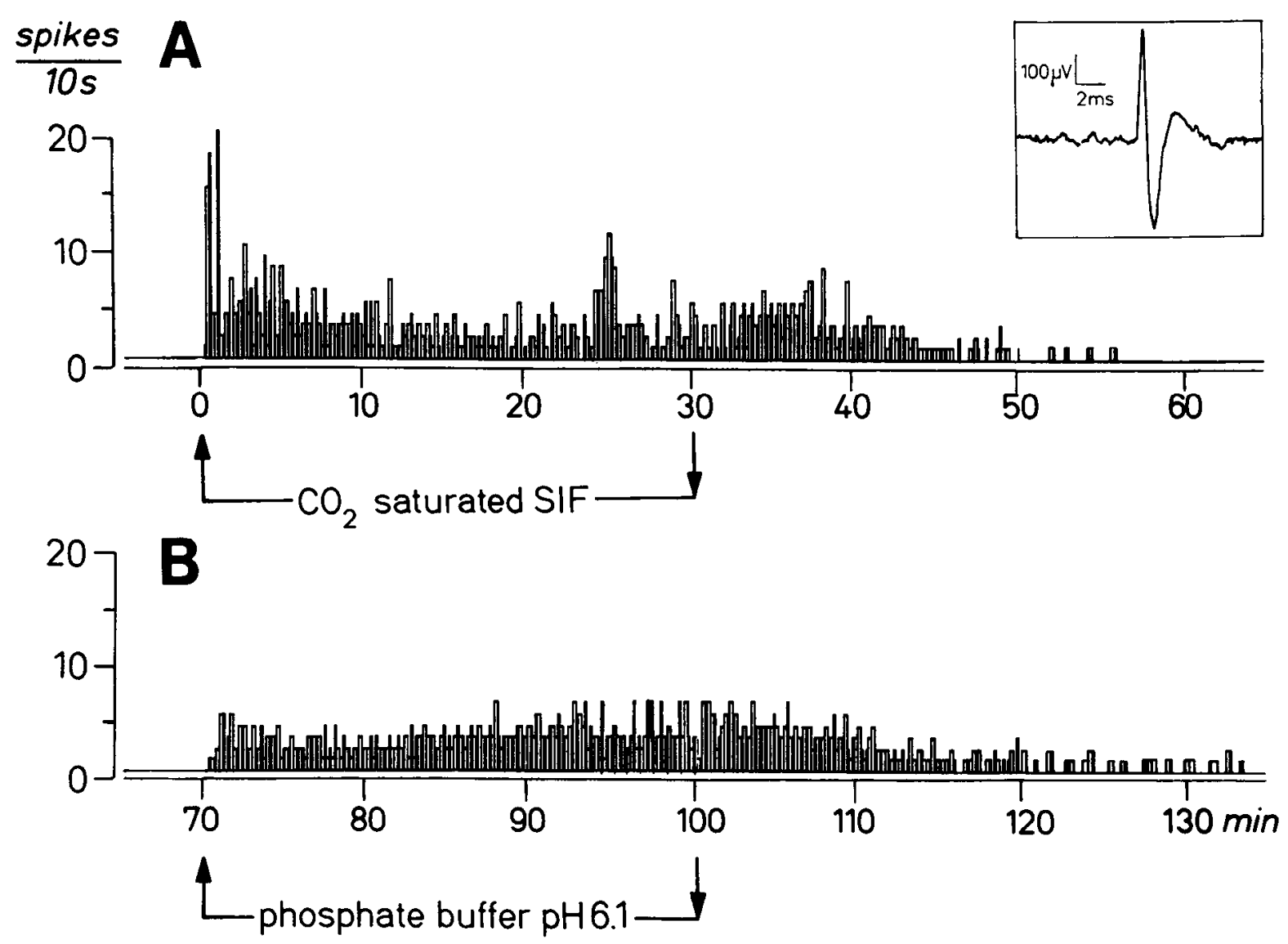

Figure 5. Spike density histograms from one C-MH fiber first treated with oxygen-free $\mathrm{CO}_{2}$-SIF $(A)$ and then superfused with oxygenated PB-SIF $(B)$. Note continuous discharge under both conditions and dynamic response in $A$ in contrast to delayed washout effects in $B$. 

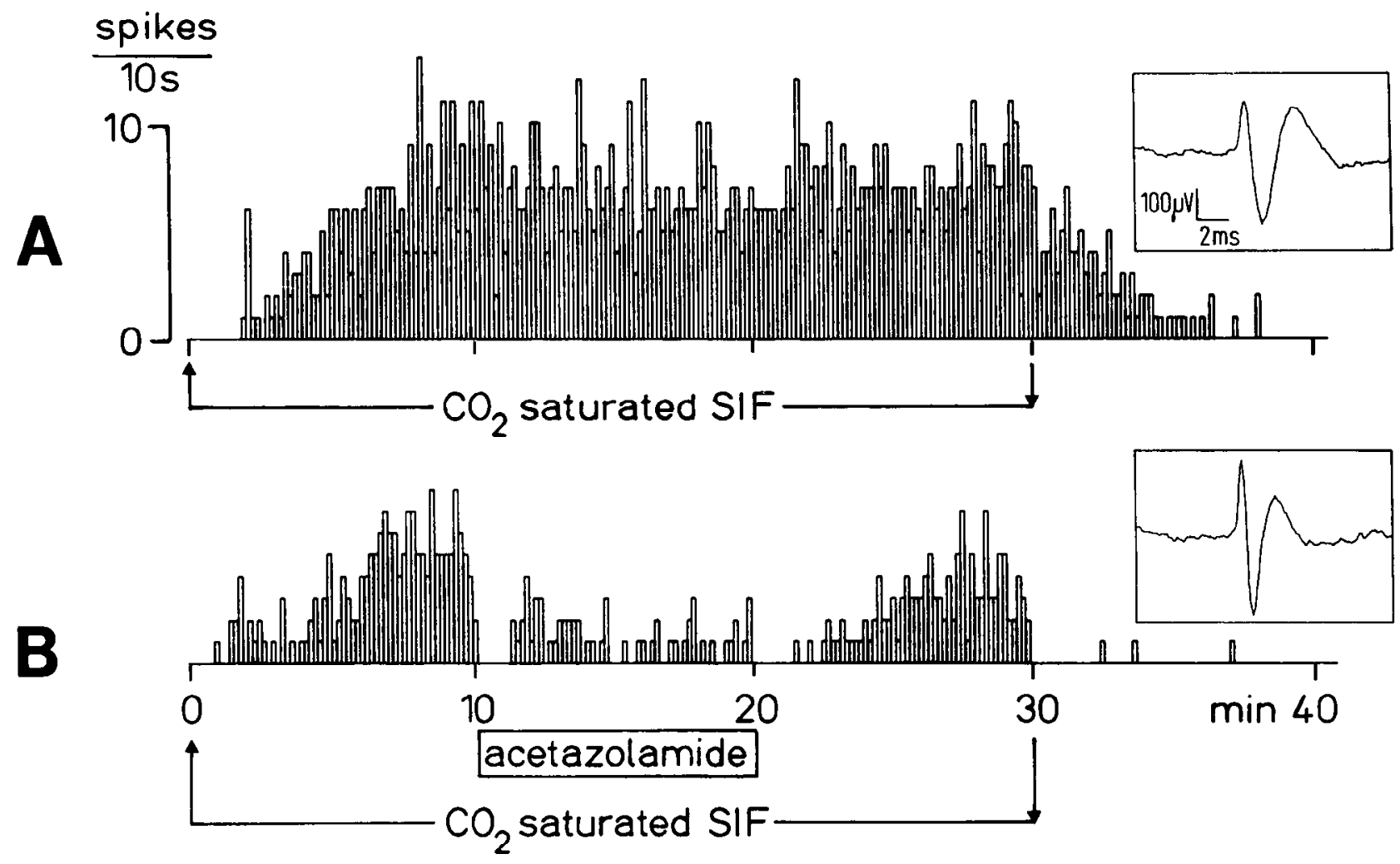

Figure 6. Spike density histograms from two C-MH fibers. $A$, Nonadapting discharge. $B$, Suppressive effect of carboanhydrase blocker acetazolamide $\left(10^{-5} \mathrm{M}\right)$, which also markedly delayed the responses of other units to short ( $5 \mathrm{~min}$ ) $\mathrm{CO}_{2}$-SIF stimuli (not shown here).

to a long diffusion time through the corium (see Lang et al., 1990, for this discussion; see also Steen and Reeh, 1991). Consequently, the response latencies were much shorter with $\mathrm{CO}_{2}$ as a source of low $\mathrm{pH}$, and they came into the latency range of algogenic inflammatory mediators like bradykinin (Lang et al., 1990). This difference between phosphate-buffered and $\mathrm{CO}_{2}-$ saturated solution points to a crucial role of the intracellular $\mathrm{pH}$, which is more rapidly decreased by the easily permeant $\mathrm{CO}_{2}$ than by a high extracellular proton concentration (Caldwell, 1958; Steenbergen et al., 1977). The idea that the intracellular hydrogen ion concentration may have to rise in order to excite the nociceptive terminals gains support from the action of acetazolamide, a carboanhydrase inhibitor, which decelerates the intracellular transformation from $\mathrm{CO}_{2}$ to protons (Thomas, 1976). As a result, it suppressed and delayed the $\mathrm{CO}_{2}$-induced responses. Histochemical carboanhydrase activity has previously been shown to exist in rabbit and human sensory, as opposed to motor, nerve fibers (Riley et al., 1988).

The nociceptor activity induced by acid $\mathrm{pH}$ followed a stimulus-response curve that was rising throughout the pathophysiologically relevant range, but seemed to fall again below that range toward $\mathrm{pH} 4.3$. In an upper $\mathrm{pH}$ range (pH 6.1-6.95), the loglog stimulus-response curve seemed to come close to the steep slopes of other nociceptive power functions (Hilgard, 1978); an exponent around 0.8 could roughly be estimated. For cerebral evoked potential amplitudes, a slope around 1 has recently been determined using an elaborated technique of graded, painful $\mathrm{CO}_{2}$ stimulation of the human nasal mucosa (Kobal and Hummel, 1990). Below pH 6.1 in our data, a smaller exponent seemed to rule the nociceptive power function until it turned downward.
A similar bend in the stimulus-response function toward lower gain has been observed when heat stimulation of polymodal nociceptors was extended to near destructive temperatures (Reeh, 1988).

The upper working range of $\mathrm{pH}$ sensitivity, $\mathrm{pH} 7-6.1$, is equipped with a second, spatial mechanism of nociceptive encoding that is the progressive recruitment of excited fibers with increasing proton concentration. The basis for this is the widely scattered $\mathrm{pH}$ thresholds that were distributed over a sevenfold range of proton concentrations ( $\mathrm{pH}$ 6.1-6.95). Spatial summation may be relevant to sensory processing in the spinal cord where convergence on dorsal horn neurons could produce an even steeper stimulus-response function in the upper $\mathrm{pH}$ range than reported here for primary nociceptive afferents.

Protons are unique among the algogenic substances in that they were able to drive nociceptors continuously without apparent tachyphylaxis or adaptation. A psychophysiological correlate has not yet been discovered (see introductory remarks), probably since injected acidic solutions are rapidly buffered by many extra- and intracellular mechanisms (Lindahl, 1961). Even the highly permeable base of a suction blister can counteract the penetration of an acidic superfusate when local vasodilatation and plasma extravasation develop, due to nociceptor excitation and direct vascular effects of low $\mathrm{pH}$. Then, the nociceptive terminals may well become embedded in a constant outward stream of normal plasma filtrate and pain may fade away, as previously reported (Keele and Armstrong, 1964).

An ample mixture of inflammatory mediators (see introductory remarks) could induce sustained nociceptor discharge for $30 \mathrm{~min}$, but a $10^{-5} \mathrm{M}$ concentration was needed (Reischl, Steen 




Figure 7. Thresholds to punctate pressure stimulation of a C-MH fiber that was not excited by $\mathrm{CO}_{2}$-SIF but was sensitized to von Frey hairs. Note rebound desensitization that was reversed by resumed $\mathrm{CO}_{2}-\mathrm{SIF}$ stimulation.

and Reeh, unpublished observations), which was, at least for bradykinin and prostaglandin $\mathrm{E}_{2}$, much higher than actually found in inflamed tissue (see Handwerker and Reeh, 1991). Since protons were effective in pathophysiologically relevant, submicromolar concentrations, one could infer that the nociceptive system prefers the $\mathrm{pH}$ as an indicator of longer-standing pathological conditions in the tissue. Such acidic states are often caused by ischemia and local hypoxia. It was therefore interesting that the present experiments confirmed the relative resistance of nociceptive $\mathrm{C}$-fibers to lack of oxygen. The $\mathrm{CO}_{2}$ saturation of the receptive field environment did not prevent continuous firing for $30 \mathrm{~min}$, or the subsequent sensitization to mechanical stimuli. From tourniquet experiments, it is well known that it takes more than $1 \mathrm{hr}$ of complete ischemia to block nociception in a human limb.

\section{Possible mechanism}

The proton-induced nociceptor excitation reported here corresponds in several details to properties of a recently discovered depolarizing current in rat sensory ganglion cells that was specifically gated by downward steps in extracellular $\mathrm{pH}$ (Bevan and Yeats, 1991). It occurred in a portion (40\%) of predominantly small, cultured dorsal root ganglion cells from which $\mathrm{C}$-fibers originate in vivo. Similar to the nociceptors, the sustained cation inward current showed $\mathrm{pH}$ thresholds between 6.1 and 6.6 in individual cells, half-maximal activation around $\mathrm{pH}$ 5.75 , and a saturation between $\mathrm{pH} 5.1$ and 5.4. Inactivation was very slow; almost constant ion fluxes were observed with whole-cell patch clamp for test periods of up to $1 \mathrm{~min}$. This channel type may well provide a molecular basis for the longlasting nociceptor excitation described here. The slow inactivation is decisively different from other proton-induced but transient sodium currents discovered previously in sensory gan-

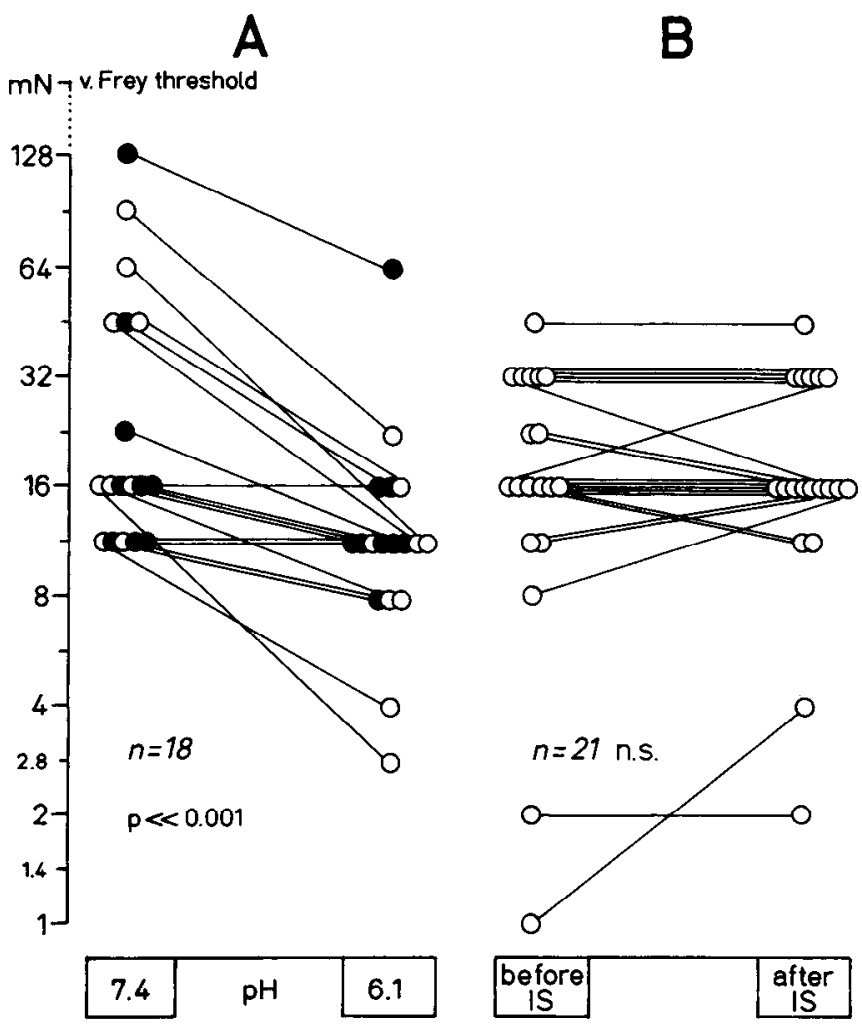

Figure 8. Summary of chemical effects on mechanical (von Frey) thresholds of different $\mathrm{C}-\mathrm{MH}$ fibers. $A, p H 7.4$ represents the baseline value. $p H 6.1$ means that units were exposed three times to $\mathrm{pH} 6.1$ stimuli $(5 \mathrm{~min})$ at $10 \mathrm{~min}$ interval $\left(2 \times \mathrm{CO}_{2}-\mathrm{SIF}, 1 \times \mathrm{PB}-\mathrm{SIF}\right)$. See text for further methodical details (e.g., "blind" testing procedure). Half of the fibers were not excited or "activated" by these treatments (solid data points). The sensitizing effect (Wilcoxon test) was larger the higher the initial threshold (rank correlation, 0.75 ). $B$, As a control, data from another study (Kessler et al., 1989), following the same time protocol, are displayed in which units were exposed to a $10^{-5} \mathrm{M}$ mixture of bradykinin, 5-HT, histamin, and prostaglandin $\mathrm{E}_{2}$ at $\mathrm{pH} 7.0$ ("inflammatory soup").

glion cells of different species (Krishtal and Pidoplichko, 1980; Konnerth et al., 1987; $\Lambda$ kaike et al., 1990). The latter currents seem to flow through proton-transformed calcium channels and are readily blocked by calcium antagonists such as diltiazem that are not known to have analgesic actions; the inactivation time constants have been measured in the order of seconds (Konnerth et al., 1987; Akaike et al., 1990). In spite of that, a role in nociception has been speculated (Krishtal and Pidoplichko, 1980). Such a role for the transient sodium currents would actually be conceivable during the sudden onset of an acidification, as in our experiments, and would explain the dynamic responses predominantly seen with $\mathrm{CO}_{2}$ stimulation. The $\mathrm{pH}$ activated sustained inward current also develops from a transient, dynamic overshoot (Bevan and Yeats, 1991).

Bevan and Yeats (1991), examining the sustained cation current, described some striking similarities between the action of hydrogen ions and that of the sensory neurotoxin capsaicin, suggesting that both may affect the same ion channel. In view of the similarities in $\mathrm{pH}$ sensitivity of sensory ganglion cells and of nociceptive nerve endings, one could expect all pH-sensitive primary afferents to be excited by capsaicin and vice versa, but this was definitely not the case. One may speculate about this 
discrepancy, but any one interpretation needs further experiments.

\section{Sensitization and hyperalgesia}

Sensitization to mechanical stimuli is certainly a major constituent of hyperalgesia accompanying human diseases as one source of chronic pain. In animal models of deep pain, sensitization of mechanonociceptors could readily be demonstrated to result from the induction of experimental inflammation (Schaible and Schmidt, 1985). The effect could directly be mimicked by the application of inflammatory mediators bradykinin and prostaglandin (Neugebauer et al., 1989; Wedekind et al., 1989). In cutaneous models, however, sensitization to mechanical stimuli remained somewhat enigmatic. Only a small subpopulation of specialized nociceptors, the high-threshold mechanoreceptive A $\delta$-fibers, in the rat have thus far been shown to lower their threshold to mechanical (von Frey) stimuli in response to cutaneous injury (Reeh et al., 1987). Obvious signs of sensitization due to cutaneous inflammation have been found higher up in the somatosensory pathway, in the spinal dorsal horn, in the thalamus, in reflex measurements, and in behavioral tests (Woolf, 1983; Guilbaud et al., 1987; Kayser and Guilbaud, 1987; Woolf and King, 1990). However, the mechanical (von Frey) thresholds of the most frequent and important nociceptor type, the "polymodal" C-MH fibers, remained unchanged by cutaneous inflammations and by applications of inflammatory mediators (Reeh et al., 1986; Kocher et al., 1987; Lang et al., 1990). This was in contrast to the transient nociceptor sensitization to heat stimuli that was readily achieved in such experiments. The enigma cannot be resolved by the present work, but at least a chemical condition, local acidosis, can now be reported that effectively lowers the von Frey thresholds of a majority of cutaneous nociceptors and is present in many diseases. The decrease of mechanical thresholds is not sufficient to explain allodynia, pain due to blowing or gently stroking the skin as in neuralgias, but it may well contribute to inflammatory hyperalgesia by increasing the number and probably the discharge rate of nociceptors activated by a given mechanical stimulus.

Protons in high concentration are an important but certainly not the general chemical mediator of pain. Other endogenous agents have algogenic actions or influence the algogenic sensitivity. 'Thus, it will be interesting to investigate whether protons interact with mediators of inflammation and to evaluate the rclativc significance of acid $\mathrm{pH}$ in inflammatory pain.

\section{References}

Akaike N, Krishtal OA, Maruyama T (1990) Proton-induced sodium current in frog isolated dorsal root ganglion cells. J Neurophysiol 63: 805-813.

Bevan S, Yeats J (1991) Protons activate a cation conductance in a sub-population of rat dorsal root ganglion neurones. J Physiol (Lond) 433:145-161.

Bretag AH (1969) Synthetic interstitial fluid for isolated mammalian tissue. Life Sci 8:319-329.

Caldwell PC (1958) Studies on the internal pH of large muscle and nerve fibres. J Physiol (Lond) 142:22-62.

Fleischer E, Handwerker HO, Joukhadar S (1983) Unmyelinated nociceptive units in two skin areas of the rat. Brain Res 267:81-92.

Guilbaud G, Benoist JM, Kayser V, Neil A (1987) Responses of ventrobasal thalamic neurones to carrageenan-induced inflammation in the rat. In: Fine afferent nerve fibers and pain (Schmidt RF, Schaible H-G, Vahle-Hinz C, eds), pp 411-425. Weinheim: VCH.
Häbler C (1929) Über den K- und Ca- Gehalt von Eiter und Exsudaten und seine Beziehungen zum Entzündungsschmerz. Klin Wochenschr 8:1569-1572.

Häbler C (1930) Untersuchungen zur Molekularpathologie der Gelenkexsudate und ihre klinischen Ergebnisse. Arch Klin Chir 156:2042.

Handwerker HO, Reeh PW (1991) Pain and inflammation. In: Proceedings of the VIth World Congress on Pain (Bond MR, Charlton JE, Wolf CE, eds), pp 59-70. Amsterdam: Elsevier.

Handwerker HO, Reeh PW, Steen KH (1990a) Effects of 5HT on nociceptors. In: Serotonin and pain (Besson J-M, ed), pp 1-15. Amsterdam: Elsevier.

Handwcrker HO, Stcen KH, Rech PW (1990b) Excitation and sensitization of nociceptors by acid $\mathrm{pH}$ in rat skin, in vitro. Soc Neurosci Abstr 16:415.

Hilgard ER (1978) Pain perception in man. In: Handbook of sensory physiology, Vol 8 (Held R, Leibowitz HW, Teuber H-L, eds), Chap 27. Heidelberg: Springer

Jacobus WE, Taylor GJ, Hollis DP, Nunnally RL (1977) Phosphorus nuclear magnetic resonance of perfused working rat hearts. Nature 265:756-758.

Kanaka R, Schaible H-G, Schmidt RF (1985) Activation of fine articular afferent units by bradykinin. Brain Res 327:81-90.

Kayser V, Guilbaud G (1987) Local and remote modifications of nociceptive sensitivity during carrageenan-induced inflammation in the rat. Pain 28:99-107.

Keele CA, Armstrong D (1964) Substances producing pain and itch. London: Arnold.

Kessler W, Kirchhoff C, Handwerker HO, Reeh PW (1989) Substance $P$ increases nociceptor responses to mediators of inflammation in rat skin. Pfluegers Arch 413:R27.

Kobal G, Hummel T (1990) Brain responses to chemical stimulation of the trigeminal nerve in man. In: Chemical senses, Vol 2 (Green BG, Mason JR, Kare MR, eds), pp 123-139. Basel: Dekker.

Kocher L, Anton F, Reeh PW, Handwerker HO (1987) The effect of carrageenan-induced inflammation on the sensitivity of unmyelinated skin nociceptors in the rat. Pain 29:363-373.

Konnerth A, Lux HD, Morad M (1987) Proton-induced transformation of calcium channel in chick dorsal root ganglion cells. J Physiol (Lond) 386:603-633.

Krishtal OA, Pidoplichko VI (1980) A receptor for protons in the nerve cell membrane. Neuroscience 5:2325-2327.

Kumazawa T, Mizumura K, Sato J (1987) Response properties of polymodal receptors studied using in vitro testis superior spermatic nerve preparations of dogs. J Neurophysiol 57:702-711.

Lang E, Novak A, Reeh PW, Handwerker HO (1990) Chemosensitivity of fine afferents from rat skin in vitro. J Neurophysiol 63:887901.

Lindahl O (1961) Experimental skin pain. Acta Physiol Scand 51 [Suppl 179]:1-90.

Lindahl O (1974) Pain-a general chemical explanation. Adv Neurol $4: 45-47$.

Lynn B, Carpenter SE (1982) Primary afferent units from the hairy skin of the rat hind limb. Brain Res 238:29-43.

Mense S, Stahnke M (1983) Responses in muscle afferent fibres of slow conduction velocity to contractions and ischaemia in the cat. J Physiol (Lond) 342:383-397.

Neugebauer V, Schaible H-G, Schmidt RF (1989) Sensitization of articular afferents to mechanical stimuli by bradykinin. Pfluegers Arch 415:330-335.

Peer LA (1955) Transplantation of tissues. Baltimore: Williams \& Wilkins.

Perl EA (1976) Sensitization of nociceptors and its relation to sensation. In: Advances in pain research and therapy, Vol 1 (Bonica JJ, Albe-Fessard D, eds), pp 17-28. New York: Raven.

Poole-Wilson PA (1978) Measurement of myocardial intracellular pH in pathological states. J Mol Cell Cardiol 10:511-526.

Reeh PW (1986) Sensory receptors in mammalian skin in an in vitro preparation. Neurosci Lett 66:141-146.

Reeh PW (1988) Sensory receptors in a mammalian skin-nerve in vitro preparation. Prog Brain Res 74:271-276.

Reeh PW, Kocher L, Jung S (1986) Does neurogenic inflammation alter the sensitivity of unmyelinated nociceptors in the rat? Brain Res 384:42-50.

Reeh PW, Bayer J, Kocher L, Handwerker HO (1987) Sensitization 
of nociceptive cutaneous nerve fibers from the rat's tail by noxious mechanical stimulation. Exp Brain Res 65:505-512.

Revici E, Stoopen E, Frenk E, Ravich RA (1949) The painful focus. II. The relation of pain to local physico-chemical changes. Bull Inst Appl Biol 1:21.

Riley DA, Sanger JR, Matloub HS, Yousif NJ, Bain JL, Moore GH (1988) Identifying motor and sensory myelinated axons in rabbit peripheral nerves by histochemical staining for carbonic anhydrase and cholinesterase activities. Brain Res 453:79-88.

Schaible H-G, Schmidt RF (1985) Effects of an experimental arthritis on the sensory properties of fine articular afferent units. J Neurophysiol 54:1109-1122.

Steen KH, Reeh PW (1991) Actions of cholinergic agonists and antagonists on sensory nerve endings in rat skin, in vitro. J Neurophysiol, submitted.

Steen KH, Anton F, Reeh PW, Handwerker HO (1990) Sensitization and selective excitation by protons of nociceptive nerve endings in rat skin, in vitro. Pfluegers Arch 415:R106.

Steenbergen C, Deleeuw G, Rich T, Williamson JR (1977) Effects of acidosis and ischemia on contractility and intracellular $\mathrm{pH}$ of rat heart. Circ Res 41:849-858.

Thomas RC (1976) The effect of carbon dioxide on the intracellular
$\mathrm{pH}$ and buffering power of snail neurones. J Physiol (Lond) 255:715735 .

von Gaza W, Brandi B (1926) Beziehung zwischen Wasserstoffionenkonzentration und Schmerzempfindung. Klin Wochenschr 5:11231127.

von Gaza W, Brandi B (1927) Die Beseitigung des Entzündungsschmerzes durch Gewebsalkalisierung. Über die Beziehungen zwischen Wasserstoffionenkonzentration und Schmerzempfindung. Klin Wochenschr 6:11-13.

Wedekind C, Kirchhoff C, Reeh PW (1989) Phrenic nerve afferents from pig pleura, in vitro. Eur J Neurosci Suppl 2:R69.

Willis WD (1990) Electrophysiological evidence for a role of altered discharges of spinothalamic tract neurons in hyperalgesia. In: Recent achievements in restorative neurology. 3. Altered sensation and pain. Chap 17 (Dimitrijevic MR, Wall PD, Lindblom U, eds), pp 153-164. Basel: Karger.

Woolf CJ (1983) Evidence for a central component of post-injury pain hypersensitivity. Nature 306:686-688

Woolf CJ, King AE (1990) Dynamic alterations in the cutaneous mechanoreceptive fields of dorsal horn neurons in the rat spinal cord. J Neurosci 10:2717-2726. 